\title{
MONILIASIS IN ACUTE LEUKAEMIA
}

\author{
BY \\ R. LANNIGAN AND M. J. MEYNELL \\ From the Department of Pathology, University of Birmingham, and the Department of Clinical \\ Pathology, General Hospital, Birmingham
}

(RECEIVED FOR PUBLICATION SEPTEMBER 8, 1958)

The prolonged use of antibiotics, cortisone, or a combination of both has resulted in an increase in infections with monilia. With the recent advances in the treatment of acute leukaemia to include anti-metabolites, corticoids, and antibiotics, an increased incidence of monilial infections might be expected. This paper reports the clinical and necropsy findings in five cases of acute leukaemia with moniliasis which have occurred at this hospital during the past two years. Four of these were treated with 6-mercaptopurine (6-M.P.), corticoids, and antibiotics. The fifth was untreated in hospital, but probably received antibiotics for some time before admission.

\section{Case Reports}

Case 1.-D. P., a woman aged 59 years, a laundress, was first admitted on September 7, 1955, complaining of dyspnoea, fatigue, and sore throat. A blood count showed: haemoglobin 7.7 g. per $100 \mathrm{ml}$., white blood cells 12,000 per c.mm., platelets 26,000 per c.mm. A differential count showed $50 \%$ myeloblasts.

Procaine-penicillin, 100,000 units b.d., 6-M.P., $25 \mathrm{mg}$. five times daily, and cortisone, $50 \mathrm{mg}$. b.d., were given. Because of a falling blood count 6-M.P. was reduced to $25 \mathrm{mg}$. b.d. and terramycin, $250 \mathrm{mg}$. six-hourly, was substituted for penicillin. Bronchopneumonia developed and the antibiotic was changed to erythromycin, 2 g. daily. The patient was discharged much improved on 6-M.P., $25 \mathrm{mg}$. b.d., and prednisone, $25 \mathrm{mg}$. b.d.

She was admitted the second time on January 12, 1956, complaining of sore throat. A blood count showed: haemoglobin $10 \mathrm{~g}$. \%, white blood cells 2,300 per c.mm., with a normal differential count. The patient died four days after admission.

Necropsy.-There was purpura of the arms and extensive ulceration and crusting with a yellowishwhite membrane on the posterior third of the tongue, epiglottic folds, pharynx, and oesophagus. There were submucosal haemorrhages in the stomach and intestines, and extensive bronchopneumonia. The red marrow occupied the entire femoral shaft. Findings in the other organs were not relevant.

Histology. - The oesophagus was extensively ulcerated with numerous mycelia on the surface and in the deeper tissues. The inflammatory exudate was largely lymphocytic and mononuclear, but occasional polymorphs were present. The lungs showed suppurative bronchopneumonia, but fungi were not detected in the lesions. The bone marrow was extensively replaced by leukaemic cells, but they had not infiltrated the liver, spleen, or kidneys. The spleen showed numerous iron-containing macrophages.

Case 2.-N. K., a woman aged 45, a housewife, was first admitted on October 28, 1955, as an emergency with prolapsed bleeding piles. A blood count showed: haemoglobin $8.9 \mathrm{~g}$. per $100 \mathrm{ml}$.; white blood cells 1,900 per c.mm., platelets 36,000 per c.mm., and a differential count, showing granulopenia with $17 \%$ lymphoblasts. A marrow puncture showed $75 \%$ lymphoblasts.

Treatment was with blood transfusions, 6-M.P., $50 \mathrm{mg}$. b.d., and prednisone, $5 \mathrm{mg}$. six-hourly. A small but definite haematological improvement occurred, and the patient was discharged still receiving 6-M.P., $50 \mathrm{mg}$. b.d., and prednisone, $25 \mathrm{mg}$. b.d. She was admitted for the second time in December 7, 1955, complaining of pyrexia, diarrhoea, and sore throat.

The epiglottis and soft palate were diffusely ulcerated, and cultures produced a profuse growth of Monilia albicans. The blood picture showed a relapse which was treated with blood transfusions, and the dosage of 6-M.P. reduced to $25 \mathrm{mg}$. daily. One per cent. gentian violet was applied locally to the mouth, and achromycin, $1 \mathrm{~g}$. daily, was given because of pyrexia. She was discharged clinically and haematologically improved. She remained well as an out-patient on 6-M.P., $25 \mathrm{mg}$. daily, and prednisone, $20 \mathrm{mg}$. daily. She was finally admitted on June 6, 1956, with a recurrence of the haemorrhoids and laryngitis, and a haematological relapse. Monilia was not isolated from repeated swabs of the mouth. Treatment was with blood transfusions, penicillin, 1 mega unit daily, tetracycline, 1 g. daily, 6-M.P., $25 \mathrm{mg}$. daily, and prednisone, $20 \mathrm{mg}$. daily, but there was no response and the patient died on July 1, 1956.

Necropsy.-There were ecchymoses on the arms and legs, and firm, yellowish, raised plaques and ulcerated areas on the posterior third of the tongue, tonsils, larynx, and oesophagus. Ulcers with raised edges and yellowish, necrotic centres were found in 
the stomach, duodenum, small intestine, and, to a lesser extent, in the ascending colon. Massive haemorrhage had occurred into the wall of the caecum and the retroperitoneal tissues. The liver was enlarged and pale with numerous firm, yellowish nodules approximately $1 \mathrm{~cm}$. in diameter in both lobes. The spleen was enlarged (300 g.) and brown. The lymph nodes were not enlarged. The bone marrow was red in the upper third of the shaft of the femur. There were no other relevant findings.

Histology.-The oesophageal lesions were similar to those in Case 1. The ulcers in the stomach and intestines showed necrosis in the centre with numerous fungi on the surface and in the deeper tissues. At the margins of the ulcers, areas of necrosis were present in the submucosa and these also contained large numbers of mycelia (Fig. 1). The cellular reaction consisted of lymphocytes, histiocytes, and occasional plasma cells. Many cells showed pyknosis and karyorrhexis and it is possible that some were leukaemic. The nodules in the liver consisted of extensive areas of necrosis with a cellular exudate of lymphocytes, plasma cells, and mononuclears (Fig. 2). Mycelia and yeast forms were found in large numbers. The nodules were sharply demarcated from the surrounding liver tissue and in some there was early fibrosis at the periphery. There was no evidence of leukaemic infiltration of the liver.

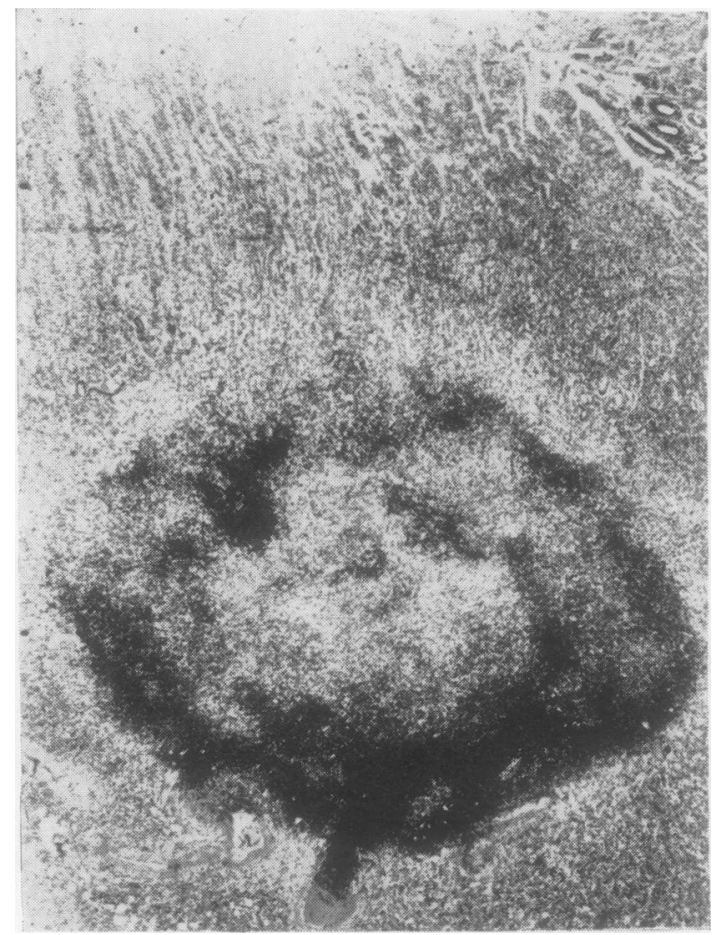

FIG. 1.-Lesion in submucosa of stomach. Masses of fungi are present. Case 2. P.A.S. $\times 25$.

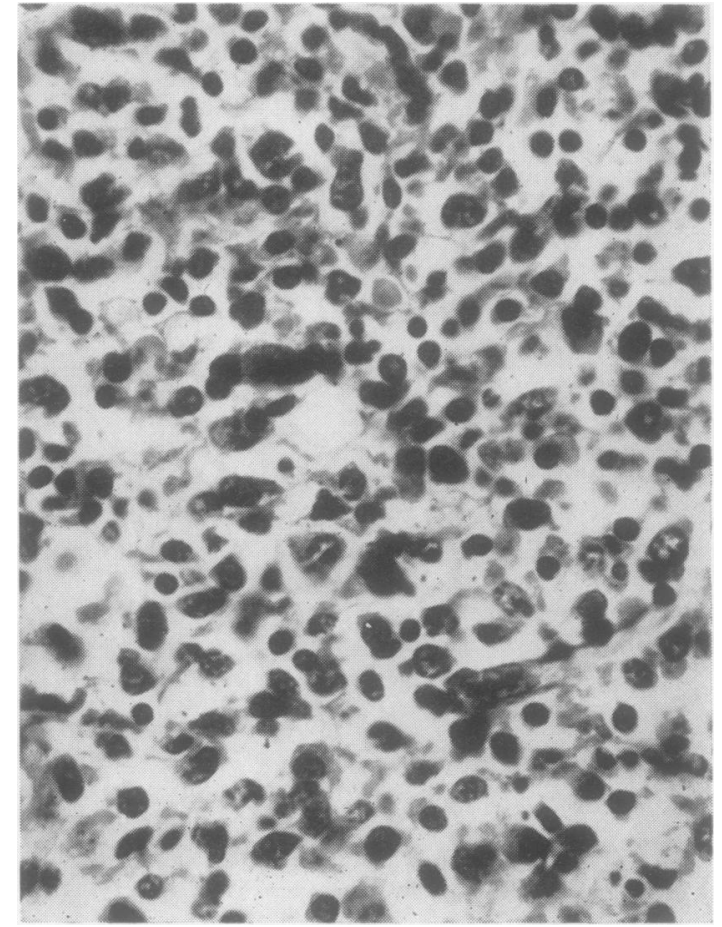

FIG. 2.-Edge of liver lesion showing cellular reaction of lymphocytes, mononuclears, and plasma cells. Case 2. Haematoxylin and eosin $\times 560$.

Cells resembling leukaemic cells were found throughout the pulp of the spleen, but the architectural pattern was preserved. Numerous ironcontaining macrophages were present. The bone marrow was extensively replaced by leukaemic cells. Other organs showed no relevant features.

Case 3.-C. L., a man aged 22, a machinist, was first admitted on March 5, 1955, complaining of dyspnoea and a haemorrhagic rash for three weeks. His temperature was $101^{\circ} \mathrm{F}$. A blood count showed: haemoglobin $4.1 \mathrm{~g}$. per $100 \mathrm{ml}$, white blood cells 10,100 per c.mm., platelets 23,000 per c.mm., a differential count showing $36 \%$ lymphoblasts.

Treatment was with blood transfusions, crystalline penicillin, 1 mega unit six-hourly, 6-M.P., $25 \mathrm{mg}$. five times daily, and cortisone, $25 \mathrm{mg}$. six-hourly. There was some haematological improvement, and the patient was discharged on cortisone and 6-M.P.

The patient was admitted for the second time on May 2, 1955, with an abscess of the groin, which was treated with achromycin, $250 \mathrm{mg}$. six-hourly, cortisone, $25 \mathrm{mg}$. six-hourly, and 6-M.P., $25 \mathrm{mg}$. five times a day. The dose of 6-M.P. was reduced to $50 \mathrm{mg}$. daily because of granulopenia. He was discharged clinically and haematologically improved, and continued on 6-M.P. and cortisone as an outpatient and had a complete haematological remission. 
He was admitted for the third time on January 30 , 1956, with an indolent leg ulcer, still in a haematological remission. $\mathrm{He}$ was continued on 6-M.P. and cortisone. The patient was admitted for the fourth time on May 11, 1956, with a cervical abscess from a septic tooth. $\mathrm{He}$ was treated with achromycin, $250 \mathrm{mg}$. six-hourly. The abscess slowly subsided, but the blood picture showed a relapse. He was discharged on cortisone and 6-M.P. He was finally admitted on August 9, 1956, acutely ill. He had pains in the chest, the liver was enlarged and tender, and the blood picture showed a relapse. Treatment was continued, but he deteriorated and died on September 4.

Necropsy.-There was diffuse brown pigmentation of the skin and multiple petechial haemorrhages. The fauces, uvula, epiglottis, and upper half of the oesophagus showed extensive ulceration and a yellowish white membrane on the surface. The stomach contained four small ulcers with raised edges. The intestines were normal. The liver was grossly enlarged and contained multiple yellowish nodules, $1-2 \mathrm{~cm}$. in diameter. The right lobe contained a large yellowish mass, $12 \mathrm{~cm}$. in diameter. The spleen showed yellowish nodules, $2-3 \mathrm{~cm}$. in diameter. Similar rounded nodules, $1 \mathrm{~cm}$. in diameter, were found in the lungs, especially at the periphery. The upper two-thirds of the femur contained reddish marrow. There were no other relevant findings.

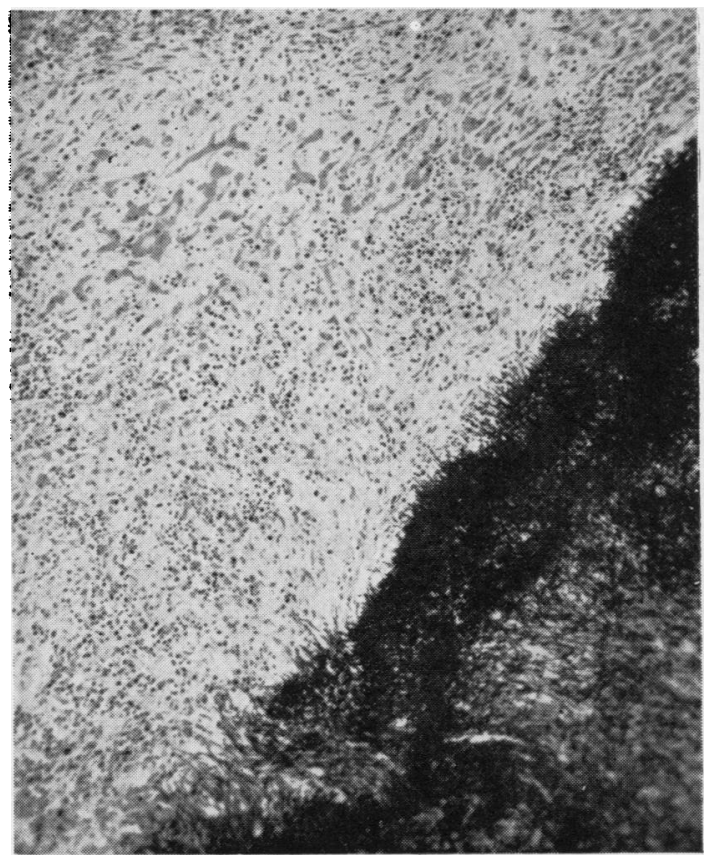

Fig. 3.-Liver nodule with masses of fungi and a peripheral cellular reaction. Case 3. P.A.S. $\times 75$.

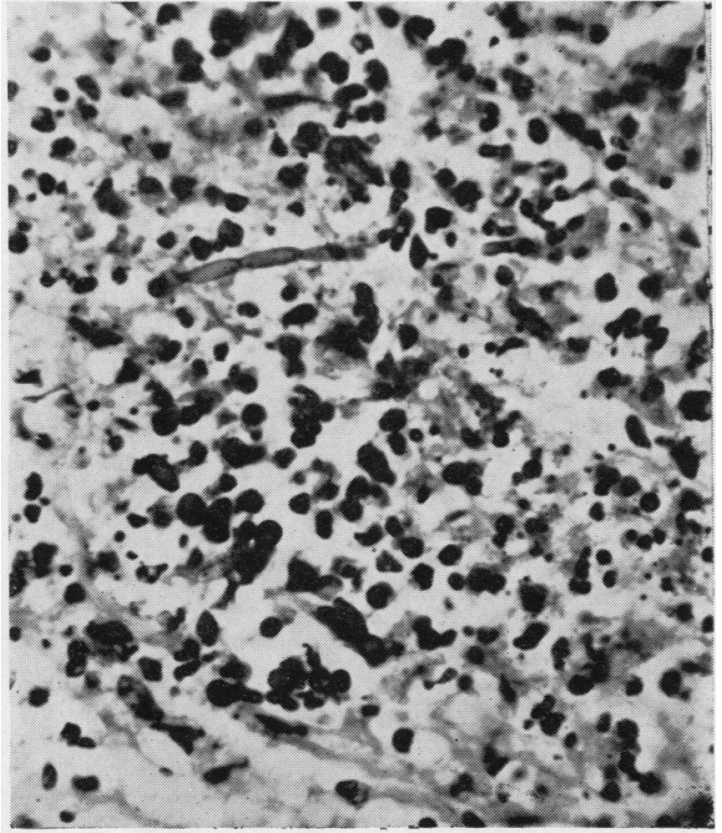

FIG. 4.-Extensive pyknosis and karyorrhexis in a liver nodule. Occasional mycelia and yeast forms are present. Case 3. Haematoxylin and eosin $\times 560$.

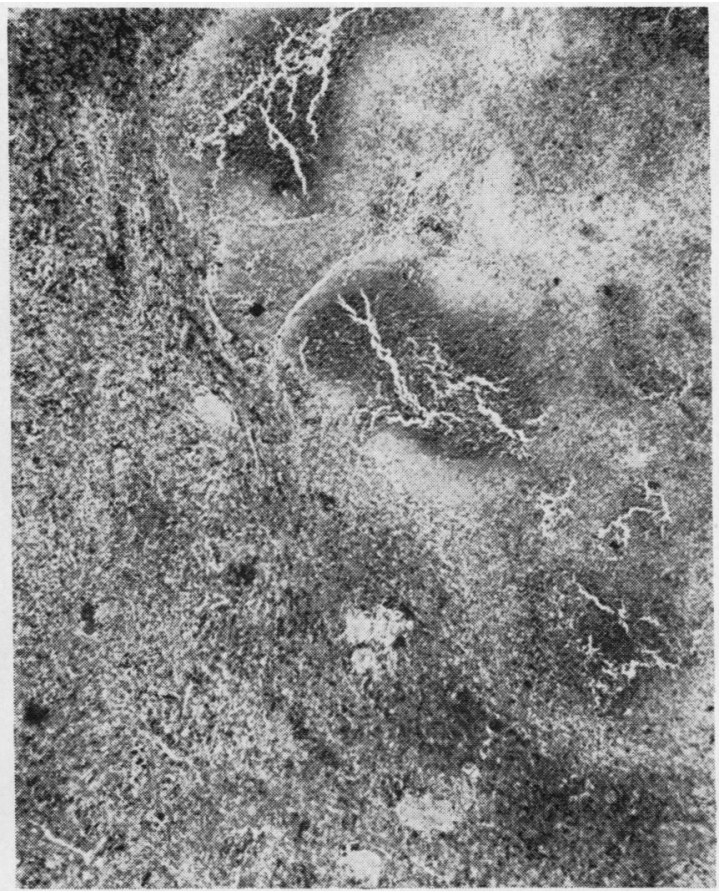

FIG. 5.-Nodule in spleen with extensive necrosis. A heavy deposit of iron pigment is seen in the surrounding tissue. Case 3. Haematoxylin and eosin $\times 25$. 


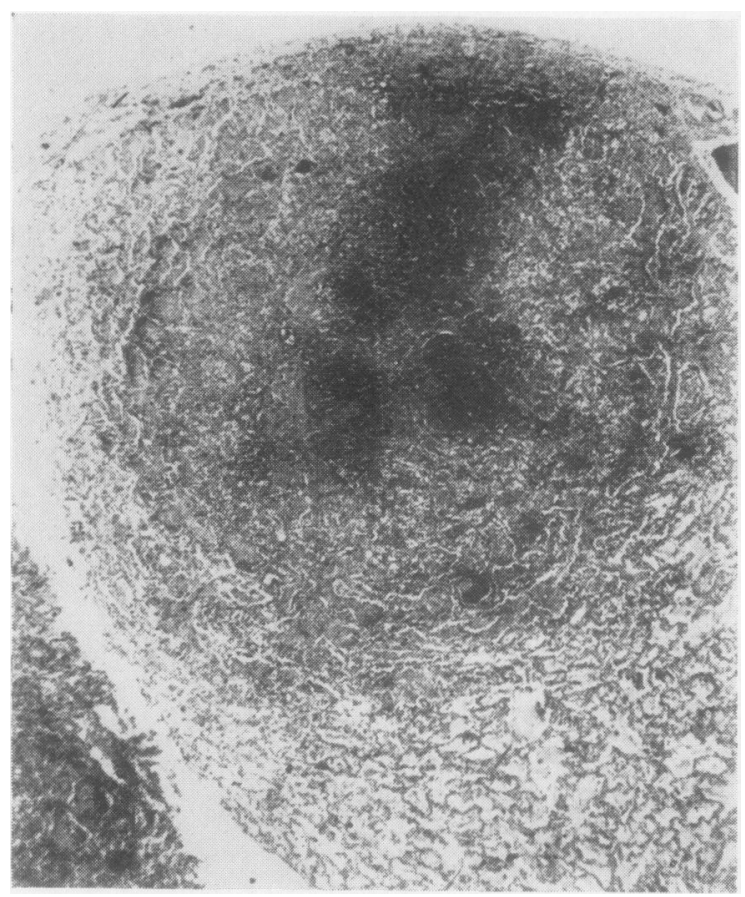

FIG. 6.-Sharply demarcated nodule in lung with central necrosis. Case 3. Haematoxylin and eosin $\times 25$.

Histology.-The lesions in the oesophagus and stomach were similar to those in Case 2. The liver nodules showed zones of necrosis and a cellular exudate of mononuclears and lymphocytes. Numerous mycelia and yeast forms were found in the necrotic areas and between the cells (Fig. 3). As in Case 2 there was extensive pyknosis and karyorrhexis (Fig. 4). The large nodule in the right lobe showed similar appearances to the smaller nodules, but there was much more cellular reaction. There was no evidence of leukaemic infiltration in other parts of the liver. The nodules of the spleen showed a structure similar to those in the liver (Fig. 5). Numerous iron-containing phagocytes were present, but there was no evidence of leukaemic infiltration. The nodules in the lungs appeared similar to those in liver and spleen, but there was more cellular necrosis (Fig. 6). Numerous mycelia and yeast forms were present. A cervical lymph node showed necrosis, and fungi could be demonstrated in small numbers. The marrow was extremely hypoplastic and contained numerous iron-containing phagocytes.

Case 4. - J. W., a woman aged 57, a housewife, was first admitted on April 15, 1955, complaining of dyspnoea, fatigue, and pain in the chest for two days. The temperature was $102^{\circ} \mathrm{F}$., and she had a left lower lobe pneumonia. A blood count showed: haemoglobin $9.5 \mathrm{~g}$. per $100 \mathrm{ml}$., white blood cells 5,300 per c.mm., and a differential count showed
$1.5 \%$ myeloblasts. She was treated with penicillin, $1 \mathrm{mega}$ unit, and terramycin, $2 \mathrm{~g}$. daily, for one week. A tentative diagnosis of diffuse carcinoma was made because of the blood picture. The patient improved and was discharged.

She was admitted finally on September 1, 1956, complaining of lassitude and mouth ulcers. A blood count gave: haemoglobin $4.4 \mathrm{~g}$. per $100 \mathrm{ml}$., white blood cells 550 per c.mm., platelets 10,000 per c.mm. ; blood films showed $1 \%$ pre-myelocytes. Sternal marrow showed $38 \%$ myeloblasts.

She was treated with blood transfusions, oxytetracycline, 1 g., cortisone, 100 mg., and 6-M.P., $50 \mathrm{mg}$. daily. A throat swab on September 29 showed a moderate growth of Monilia albicans, which was treated locally with $1 \%$ gentian violet and " nystatin," one tablet $(500,000$ units) four times a day. The patient died two days later.

Necropsy.-The tonsils, epiglottis, and upper two-thirds of the oesophagus were ulcerated and covered with a firm, yellowish membrane. The stomach and colon were normal. Three ulcers with long axis transverse were found in the small intestine. One small subcapsular nodule was present in the live:. The lungs showed an extensive bronchopneumonia. The hilar and cervical lymph nodes were enlarged and necrotic. The upper two-thirds of the femur contained reddish-brown marrow. There were no other relevant findings.

Histology.-The lesions in the oesophagus and small intestine were similar to those in Cases 2 and 3, and many mycelia were present in the lesions. The subcapsular nodule of the liver was entirely necrotic. Fungi were not demonstrated. There was no evidence of leukaemic infiltration. Extensive suppurative bronchopneumonia with no demonstrable fungi was found. Extensive necrosis was found in the hilar and cervical lymph nodes, but fungi were not demonstrated. Numerous iron-containing phagocytes were in the spleen, but no evidence of leukaemic infiltration was found. The bone marrow was hypoplastic.

Case 5.-H. S., a woman aged 64 , a housewife, was admitted on May 26, 1957, complaining of anorexia, loss of weight, and sore throat. She had been treated at home for pneumonia, but the treatment was not known. She had extensive moniliasis of the tongue and palate. A blood count showed: haemoglobin $6.4 \mathrm{~g}$. per $100 \mathrm{ml}$., white blood cells 600 per c.mm. A differential count showed $20 \%$ monoblasts. The sternal marrow was hypercellular with $65 \%$ of cells of the monocytic series. The patient died four days after admission. No specific treatment was given.

Necropsy.-A few small areas of pale, white crusting were found on the anterior surface of the tongue, soft palate, and uvula. The oesophagus was extensively involved by similar lesions. The stomach and small intestine were normal, but extensive 
superficial ulceration was present in the rectum. The liver was pale but not enlarged. The spleen was normal. The cervical and para-aortic lymph nodes were enlarged. The marrow was pale brown in the upper half of the shaft of the femur. There were no other relevant findings.

Histology.-The oesophageal and rectal lesions appeared similar to those described in Cases 2 and 3. The liver, spleen, and kidneys showed no evidence of leukaemic infiltration. Reactive hyperplasia was present in the lymph nodes and the bone marrow was extensively replaced by leukaemic cells.

\section{Discussion}

Histology of the Monilial Lesions.-Nearly all the lesions showed necrosis, and the liver nodules in Case 2 were the only examples where fibrosis was noted at the periphery. The extent of the cellular reaction varied from case to case, but was predominantly lymphocytic and mononuclear with variable numbers of plasma cells. In Case 2 there is a possibility that some of the cells were leukaemic. Giant cells and foam cells as described by Ruhrmann and Adam (1955) were not found. Mycelia and yeast forms were demonstrated in large numbers within the lesions. The organisms were readily detected in routine haematoxylin and eosin preparations, but were more easily found with the periodic-acid-Schiff reagent. In all cases except Case 1 the fungi were identified by culture either during life or post mortem. In the gastro-intestinal tract the fungi were sometimes confined to the surface but often were found deeply in the tissues. Torack (1957) observed in his cases that with antibiotics alone the fungi were frequently confined to the surface in gastro-intestinal lesions, whereas in the patients receiving corticoids and antibiotics they had often penetrated to the deeper tissues. The possibility of secondary infection of leukaemic deposits was considered, but, as all lesions examined had large numbers of monilia and no uninvolved leukaemic deposits were detected, this appears to be unlikely.

Relation of Moniliasis to Treatment.-These five cases are the only examples of moniliasis in the necropsy records of the General Hospital, Birmingham, for the last 10 years. During this period necropsies have been performed on 69 cases of leukaemia, 51 of which were considered to be acute. Twelve of these cases had been treated with 6-M.P., corticoids, and antibiotics for varying periods and four showed moniliasis at necropsy. Moniliasis was encountered only once (Case 5) in the other cases, either having no specific treatment, antibiotics alone, or cortisone and antibiotics. Moniliasis was not encountered in a series of 55 necropsies on patients treated with prolonged cortisone therapy for various diseases, and half of these patients were also receiving antibiotics (Dr. K. R. Thornton, 1958, personal communication).

Since the introduction of antibiotics there has been an increased number of reported cases of gastro-intestinal and visceral involvement with monilia (Taylor and Rundle, 1952; Brown, Propp, Guest, Beebe, and Early, 1953 ; Schaberg, Hildes, and Wilt, 1955; Matthias and Rees, 1956). Occasional reports have appeared of moniliasis developing during cortisone therapy (Soffer, Levitt, and Baehr, 1950; Levy and Cohen, 1955), or after cortisone and antibiotics (Torack, 1957). A few cases of generalized moniliasis have been reported in leukaemias (Stenderup, Bichel, and Kissmeyer-Nielsen, 1956 ; Torack, 1957), and Zimmerman (1950) refers to seven cases of generalized moniliasis seen by Dr. Farber in children. Although full details of these seven cases have not apparently been published, five were of acute leukaemia treated with folic acid antagonists and antibiotics.

In view of the multiple therapeutic agents employed in four of the present cases and the debilitating type of disease, it is not possible to incriminate any particular group of drugs. Experimental evidence of an enhancing effect on the pathogenicity of monilia in experimental animals has been produced by Seligmann (1952) and Winter and Foley (1956). An enhancing effect of cortisone has been shown by Syverton et al. (1952), Seligmann (1953), and Winter and Foley (1956), but Winner (1958) believes that cortisone has no such effect. We have been unable to find experimental evidence on the effect of 6-mercaptopurine on monilia infections, but the high incidence of moniliasis in patients treated with 6-M.P., cortisone, and antibiotics suggests that 6-M.P. may further increase the risk of disseminated fungus infections.

\section{Conclusion}

Antibiotics, particularly of the broad range type, e.g., tetracyclines, should be used for limited periods only in acute leukaemia, and antifungal agents such as "nystatin" may be of value in preventing gastro-intestinal and generalized moniliasis.

We wish to thank the physicians of the General Hospital, Birmingham, for access to the clinical records. 


\section{REFERENCES}

Brown, C., Propp, S., Guest, C. M., Beebe, R. T., and Early, L. (1953). J. Amer. med. Ass., 152, 206.

Levy, E. S., and Cohen, D. B. (1955). Arch. intern. Med., 95, 118.

Matthias, J. Q., and Rees, E. G. (1956). J. Path. Bact., 71, 512.

Ruhrmann, G., and Adam, W. (1955). Virchows Arch. path. Anat., 327, 273.

Schaberg, A., Hildes, J. A., and Wilt, J. C. (1955). Arch. intern. Med., $95,112$.

Seligmann, E. (1952). Proc. Soc.exp. Biol. (N.Y.), $79,481$.

- (1953). Ibid., 83, 778.
Soffer, L. J., Levitt, M. F., and Baehr, G. (1950). Arch. intern. Med., $86,558$.

Stenderup, A., Bichel, J., and Kissmeyer-Nielsen, F. (1956). Lancet, 1,20 .

Syverton, J. T., Werder, A. A., Friedman, J., Roth, F. J., Graham, A. B., and Mira, O. J. (1952). Proc. Soc. exp. Biol. (N.Y.), 80, 123.

Taylor, T., and Rundle, J. A. (1952). Lancet, 1, 1236.

Torack, R. M. (1957). Amer. J. Med., 22, 872.

Winner, H. I. (1958). Proc. roy. Soc. Med., 51, 496.

Winter, W. D., and Foley, G. E. (1956). J. infect. Dis., 98, 150.

Zimmerman, L. E. (1950). A.M.A. Arch. Path., 50, 591. 